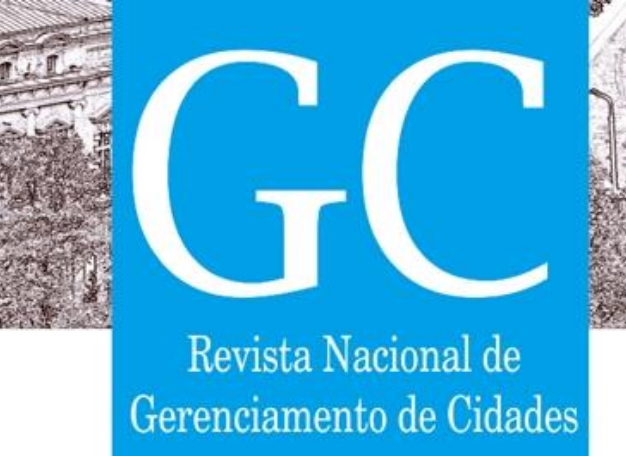

\title{
Análise do gerenciamento de resíduos da construção civil (RCC) em um município de pequeno porte
}

\author{
Analysis of constrution and demolition waste (CDW) management in a small \\ municipality
}

Análisis de gestión de residuos de construcción $(R C C)$ en un pequeño municipio

\section{Galilleu Silva}

Mestrando em Engenharia Aplicada e Sustentabilidade, Engenheiro Ambiental, IF Goiano, Brasil galilleu@live.com

\section{Adriana Antunes Lopes}

Professora Doutora em Ciências da Engenharia Ambiental, Arquiteta e Urbanista, IFSP, Brasil. adriana.lopes@ifsp.edu.br

\section{Édio Damásio da Silva Júnior}

Professor Doutor em Tecnologia Ambiental e dos Recursos Hídricos, Engenheiro Ambiental, IF Goiano, Brasil. edio.damasio@ifgoiano.edu.br

Abner Santos Baroni Sales

Mestrando em Engenharia Aplicada e Sustentabilidade, Engenheiro Civil, IF Goiano, Brasil abnersantosbaroni@hotmail.com 



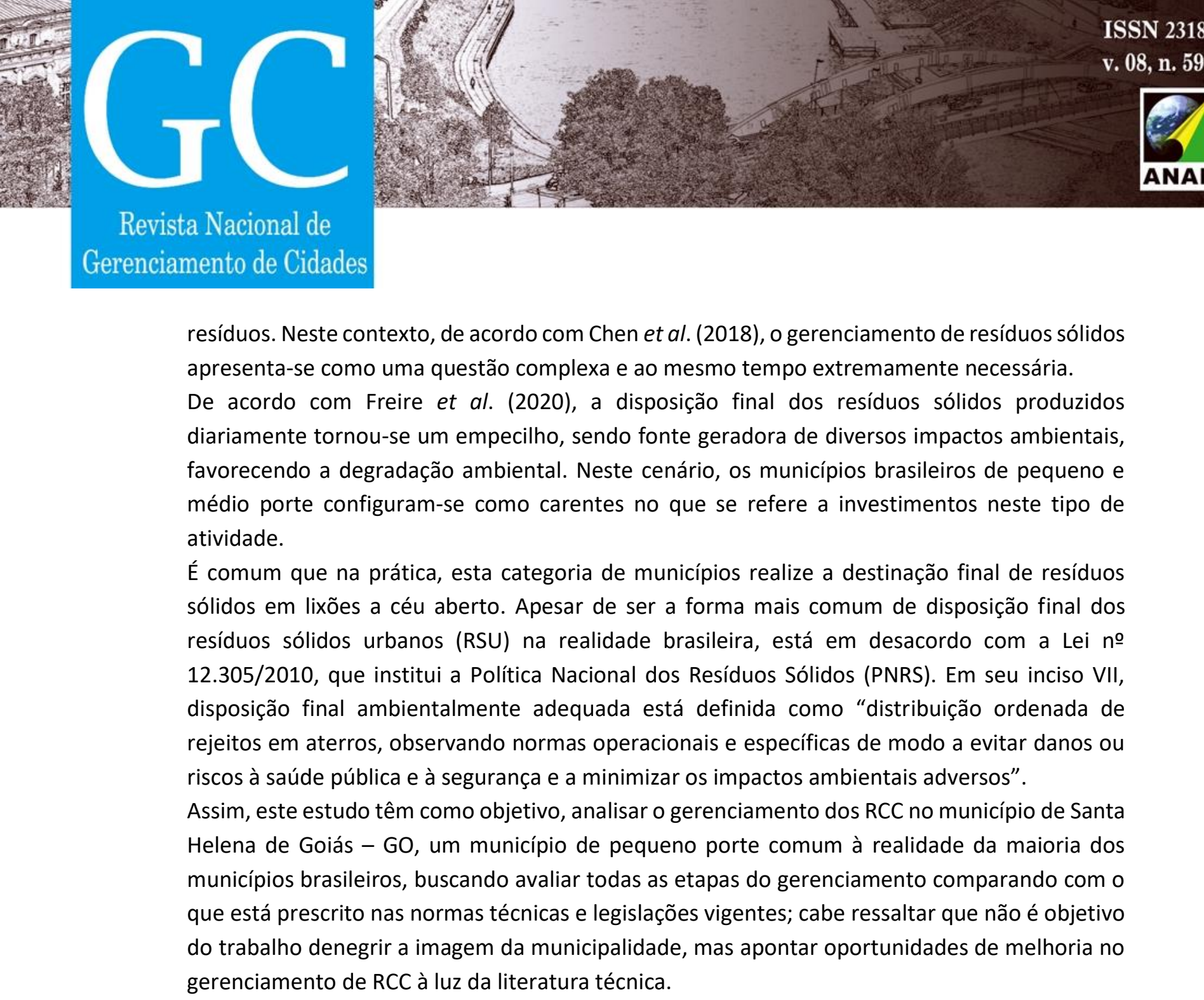

resíduos. Neste contexto, de acordo com Chen et al. (2018), o gerenciamento de resíduos sólidos aprenta-se como uma questão complexa e ao mesmo tempo extremamente necessária.

diariamente tornou-se um empecilho, sendo fonte geradora de diversos impactos ambientais, favorecendo a degradação ambiental. Neste cenário, os municípios brasileiros de pequeno e médio porte configuram-se como carentes no que se refere a investimentos neste tipo de atividade.

comum que na prática, esta categoria de municípios realize a destinação final de resíduos sólidos em lixões a céu aberto. Apesar de ser a forma mais comum de disposição final dos resíduos sólidos urbanos (RSU) na realidade brasileira, está em desacordo com a Lei no 12.305/2010, que institui a Política Nacional dos Resíduos Sólidos (PNRS). Em seu inciso VII, disposição final ambientalmente adequada está definida como "distribuição ordenada de rejeitos em aterros, observando normas operacionais e específicas de modo a evitar danos ou iscos à saúde pública e à segurança e a minimizar os impactos ambientais adversos".

Assim, este estudo têm como objetivo, analisar o gerenciamento dos RCC no município de Santa maloria dos

\section{METODOLOGIA}

O município de Santa Helena de Goiás possui uma população estimada de 38.648 habitantes (IBGE, 2019), localizado na região sudoeste de Goiás. O município já possui o Plano Municipal de Gestão de Resíduos Sólidos - PMGRS desde 2010, assim como o Plano Municipal de Saneamento Básico - PMSB desde 2015. Assim, a metodologia para análise do gerenciamento dos RCC se deu por meio do seguinte fluxograma (Figura 1).

Figura 1. Fluxograma da metodologia do trabalho.

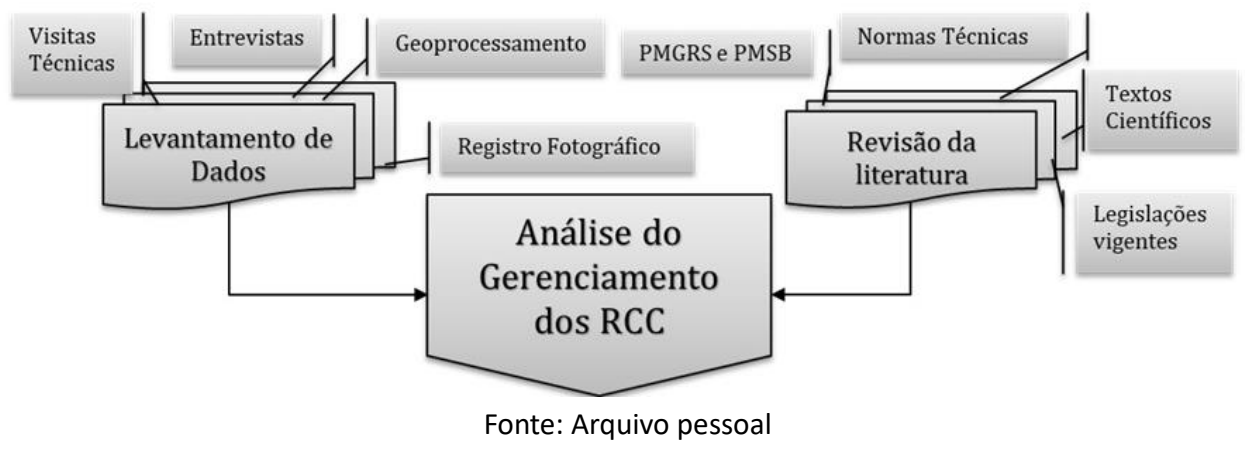





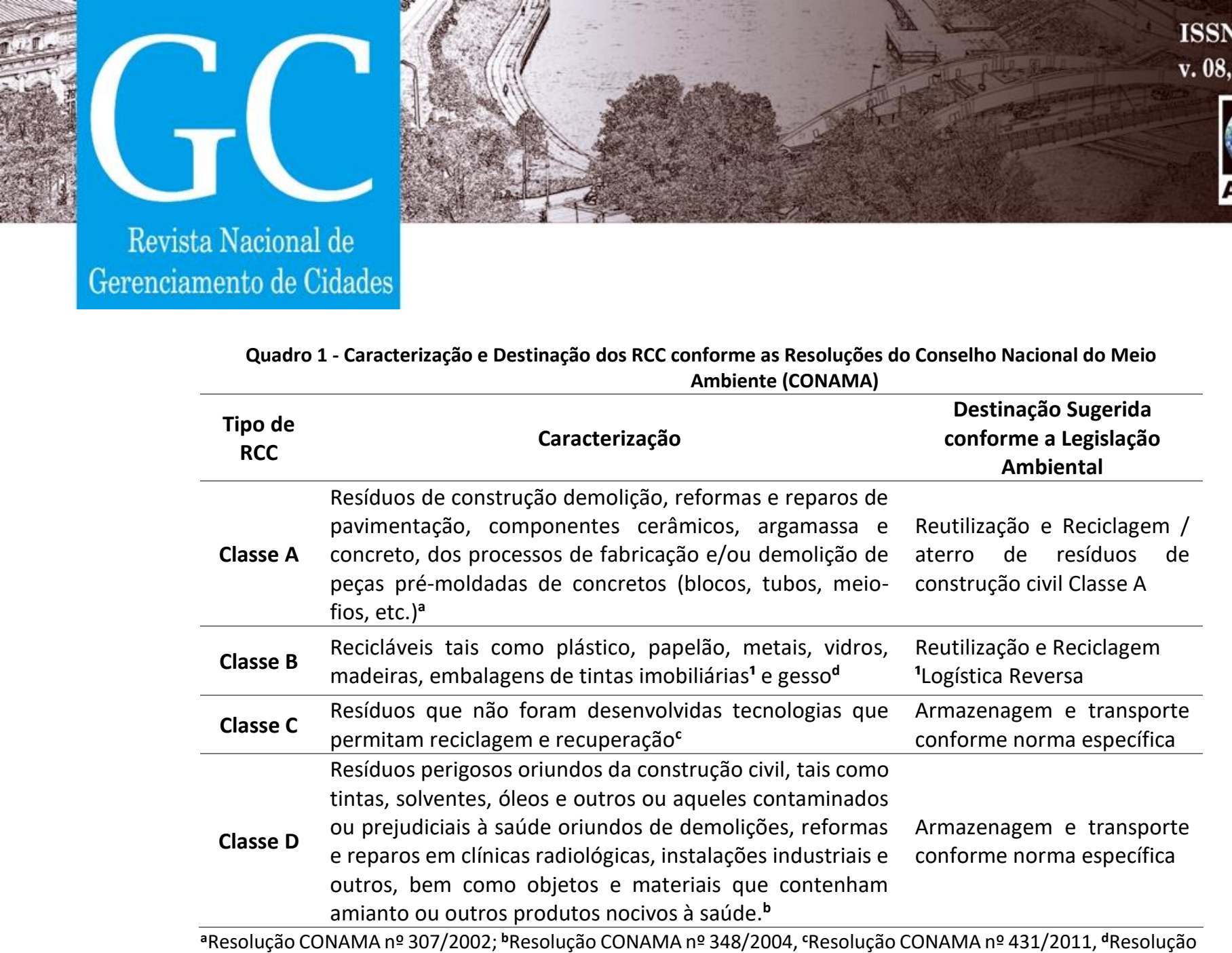

Revista Nacional de

Gerenciamento de Cidades

Quadro 1 - Caracterização e Destinação dos RCC conforme as Resoluções do Conselho Nacional do Meio Ambiente (CONAMA)

\begin{tabular}{clc}
\hline $\begin{array}{c}\text { Tipo de } \\
\text { RCC }\end{array}$ & \multicolumn{1}{c}{ Caracterização } & $\begin{array}{c}\text { Destinação Sugerida } \\
\text { conforme a Legislação } \\
\text { Ambiental }\end{array}$ \\
\hline Classe A & $\begin{array}{l}\text { Resíduos de construção demolição, reformas e reparos de } \\
\text { pavimentação, componentes cerâmicos, argamassa e } \\
\text { concreto, dos processos de fabricação e/ou demolição de } \\
\text { peças pré-moldadas de concretos (blocos, tubos, meio- } \\
\text { fios, etc.) }\end{array}$ & $\begin{array}{l}\text { Reutilização e Reciclagem / } \\
\text { aterro de resíduos de } \\
\text { construção civil Classe A }\end{array}$ \\
\hline Classe B & $\begin{array}{l}\text { Recicláveis tais como plástico, papelão, metais, vidros, } \\
\text { madeiras, embalagens de tintas imobiliárias'e gesso }\end{array}$ & $\begin{array}{l}\text { Reutilização e Reciclagem } \\
\text { 'Logística Reversa }\end{array}$ \\
\hline Classe C & $\begin{array}{l}\text { Resíduos que não foram desenvolvidas tecnologias que } \\
\text { permitam reciclagem e recuperação }\end{array}$ & $\begin{array}{l}\text { Armazenagem e transporte } \\
\text { conforme norma específica }\end{array}$ \\
\hline & $\begin{array}{l}\text { Resíduos perigosos oriundos da construção civil, tais como } \\
\text { tintas, solventes, óleos e outros ou aqueles contaminados } \\
\text { ou prejudiciais à saúde oriundos de demolições, reformas } \\
\text { e reparos em clínicas radiológicas, instalações industriais e } \\
\text { outros, bem como objetos e materiais que contenham } \\
\text { amianto ou outros produtos nocivos à saúde. }\end{array}$ & $\begin{array}{l}\text { Armazenagem e transporte } \\
\text { conforme norma específica }\end{array}$ \\
\hline
\end{tabular}
CONAMA no 469/2015.

Verifica-se na prática, que a opção de destinação final dos RCC em aterros sanitários ou em lixões a céu aberto é a principal forma de disposição final deste tipo de resíduo, contrariando o que impõe a PNRS e o que determina as resoluções vigentes do CONAMA.

Por sua vez, a opção pelos aterros sanitários se deve ao fato de esta ser atualmente a forma de disposição mais viável dentro da realidade brasileira, tanto do ponto de vista técnico quanto do ponto de vista econômico. Entretanto, suas características técnicas e construtivas são adequadas para minimizar os impactos dos resíduos sólidos urbanos (RSU) oriundos das residências e do comércio, não sendo o ideal para dispor todas as classes de resíduos provenientes da construção e demolição.

Porém, mesmo obedecendo as normas e critérios de instalação e operação de um aterro sanitário, os problemas oriundos da operação são facilmente detectados e dificilmente remediados. Assim sendo, mesmo áreas de disposição que teoricamente são rotuladas como 'aterro sanitário' ou mesmo 'aterro controlado', assumem na prática aspectos claros de 'lixão a céu aberto'.

A Política Nacional dos Resíduos Sólidos (Lei no 12.305/2010) recomenda que os resíduos sólidos com potencial para reaproveitamento ou reciclagem não devem ser encaminhados para aterros, mas sim reutilizados ou reciclados de forma a minimizar o dano ambiental. Além disso, proíbe a disposição final dos resíduos de construção civil em aterros sanitários, os quais devem receber exclusivamente os rejeitos (BRASIL, 2010). 


